\title{
THE DIFFICULTIES OF BECOMING AN E-PATIENT FROM A GOOGLE-PATIENT. A QUALITATIVE RESEARCH IN HUNGARY
}

\author{
ÉVA MÁLOVICS, GERGELY FARKAS
}

\begin{abstract}
:
Technological inventions make the health care system more democratic. The patients increasing knowledge and awareness have an essential role in this. With the help of the Internet, not only the physician can follow the behaviour and condition of the patients more closely, but the patients are also able to monitor the doctor's work effectively. The new generation of patients actively deals with their health-related issues. They gather information with search engines and online social networks, and they turn to the health care system after they possess some knowledge about their medical state. We study, how the so-called e-patients change the most often paternalistic doctor-patient relationships. We conducted interviews with patients who invest considerable energy before consultations or treatments to find out the possible causes of their condition and the treatments available on the Internet. We conducted interviews with patients with severe chronic illnesses because we assume that they are motivated in gathering knowledge about therapeutic possibilities. The research question is how they use this knowledge in the doctor-patient relationship. Results show that these patients look for new online information constantly and thoroughly about their medical state and the possible treatments. They feel that they arrive at the consultation with more knowledge about the specific illness than what the doctors have got. In the end, they cannot speak about it because of the current constraints of the medical consultations.
\end{abstract}

\section{Keywords:}

e-patient, healthcare, communication, grounded theory, information asymmetry

JEL Classification: $110,118,039$

\section{Authors:}

ÉVA MÁLOVICS, University of Szeged, Faculty of Economics and Business Administration, Hungary, Email: malovics@eco.u-szeged.hu GERGELY FARKAS, University of Szeged, Faculty of Economics and Business Administration, Hungary, Email: farkas.szte@gmail.com

\section{Citation:}

ÉVA MÁLOVICS, GERGELY FARKAS (2019). The Difficulties of Becoming an E-Patient from a Google-patient. A Qualitative Research in Hungary. International Journal of Social Sciences, Vol. VIII(1), pp. 17-30., 10.20472/SS.2019.8.1.002 


\section{Introduction}

The inefficiency and crisis of the health care system and the problems of doctor-patient communication are world phenomena. According to Le Fanu (1999) in modern medicine four paradoxes can be discovered in the health care systems of the 20th. Century:

1. Despite the successes of modern medicine, the doctors are disappointed.

2. Surveys show that the proportion of people who are concerned about their health has also increased.

3. The popularity of alternative medicine is growing.

4. The costs of the healthcare systems exceed the possibilities. (Le Fanu 1999)

This tendency seems to have led to both parties' mutual dissatisfaction and also led to some reduction in service quality. Doctor-patient communication is a classic topic, but the current suggestions for improving communication are still not working in practice. Bálint's book from 1957 published in English is still current today. Bálint collaborated with 14 practitioners at the Tavistock Clinic and described his experience in his book. Bálint points to the importance of the physician's personality as medicine and points to the problematic situation that a physician must deal with this alone since this "drug" has no dosage instructions (Bálint, 1957).

Our goal is to reveal the characteristics of the doctor-patient relationship according to the patients' experiences nowadays. We conducted interviews to know more about the patients' feelings, thoughts and experiences. We are not aiming to evaluate the current state of medical science or the health care system in Hungary. We only convey the patients' experience about them if it has influenced their behaviour. We have also made interviews with doctors on this topic, because interpersonal communication is a multi-role process, and it is essential to examine the other side as well, but we analyse the interviews with patients only in this study.

Nowadays, rapid technological development induces significant changes in the field of healthcare. Meskó (2014) writes about such changes what can make the face-to-face doctorpatient consultations disappear. The patients increasing knowledge and awareness have an essential role in this. Based on modern technology the health care returns to the homes of people (Engelen, 2014).

E-patients are not just differentiated by using the internet to gather information about their medical state, but they are empowered, engaged, equipped, and enabled. (Hewitt-Taylor, Bond, 2012) Ferguson (2007) coined the term about patients who do everything in their power to help the doctors, to play an active role in self-care. „New technologies will finally help medical professionals focus more on the patient as a human being instead of spending time hunting down pertinent information. They will be able to do what they do best: provide care with expertise. In turn, patients will get the chance to be equal partners in this process taking matters into their own hands." (Meskó, 2014, p. 15.)

Meskó (2014) expect the rapidly growing number of the e-patients soon, which allows or enforces the renewal of the medical practice. If the health care system reacts too slow, the gap can grow more extensive than they can handle. This e-patient revolution can lead to situations where the patients seek medical help in the unverified and unsafe world of the new technology. In the communication patients tends to use new tools and gadgets and doctors should follow them to make these new virtual spaces safe from a medical viewpoint.

Because of the abovementioned trends, new online social networks emerged and forming. The people actively deal with their health-related issues, gather information about their 
possible illnesses on the internet and they consult with professionals based on this new knowledge. In online social networks, the patients share their knowledge with their peers, and they advise each other based on their experiences. They feel they have a better understanding of their problems than real doctors (deBronkart, 2018). The e-patient is an engaged medical client who actively forms his/her faith and who shares his/her diagnostic data widely to get relevant second opinion. (Meskó, 2014) Not all doctors can accept it easily.

Our questions are: Do the patients with severe and chronic illness gather information about their state or treatment possibilities? Do they share the new information with their doctors? How does this influence the doctor-patient relationship? With our research, we would like to provide practical information about the needs of doctors and patients in this changing relationship. We hope, this can increase the service quality and improve communication, which became very important during technological development. We do not want to state anything in general about the public health system of Hungary. There are many factors and limitations which affect healthcare performance (Hejduková, Kureková, 2017) and communication is only one of them.

\section{The doctor-patient relationship}

Information asymmetry frequently occurs in health services. On the supply side, primary the doctors accumulate extra knowledge about the possible treatments, including the utility, the costs and the risk of these treatments. Meanwhile, the patients are in a vulnerable state. According to Katz (1984) the doctors are excellent in treating physiological needs, but they care less about their decision needs. Schwartz (2016) thinks patients' involvement in treatment raised the health service quality; however the doctors pushed too much responsibility to the patients' side. In their TED talk, based on the USA's example he states that the doctors offer several versions of treatments, describing their risks and benefits, and they let the patient choose. According to Schwartz "it really is a shifting of the burden and the responsibility for decision-making from somebody who knows something - namely, the doctor to somebody who knows nothing and is almost certainly sick and thus not in the best shape to be making decisions - namely, the patient." (Schwartz, 2016, p. 1) Schwartz (2016) prefer the conservative viewpoint where the physician has power over the patient which is partly due to the asymmetric information distribution, and the other is the patient state of consciousness what is not ideal for decision making in many cases.

Due to technological development, the risk awareness of the patients and the workers of the health care system changes a lot. While patients arrive at the doctors with knowledge about scientific debates and new inventions about their illness, the physicians try to follow the actual medical protocols.

"Because of the progression of the information society, today's patients will get into a "specialist" status for their knowledge of their symptoms. In part, this led to the concept of "lay expert" in the literature of behavioural science literature." (Csabai, Csörsz, Szili, 2009, p. 18) Some doctors take it as a personal, or professional offence, which can lead to worse communication and distrust.

Klemperer (2005) distinguishes three models of doctor-patient communication: paternalistic, informative, and shared decision making (SDM). The paternalistic is the same as the above mentioned physician focused communication. Informative means the patient decides about the treatment. According to Klemperer (2005), these only small segments of patients prefer this. The majority would need more information and participation in the decision-making about the treatment. (Klemperer 2005) 
In the literature (Herrman et al. 2005), more and more people argued that paternalistic communication is not very effective because it does not care much with the needs and ideas of the patients. Instead, the doctor and the patient should establish a cooperative relationship. Kincsesné Vajda (2013) found that paternalistic communication is dominant in Hungary and our results will strengthen this.

\section{From the Google patient to the e-patient}

Csabai and her colleagues (2009) write about shared decision making as the model of concordance in doctor-patient relationships. They think it is possible for a physician and a patient to meet as professionals, however, similar knowledge is not the only condition to make this communication peer-to-peer. One of the most critical obstacles is the "false contract" in the minds of the parties. They misunderstand each other roles and therefore except something else from the situation. Patients think they only need to answer the questions, and the doctor will take responsibility for their health. Doctors think the secrecy is the patients' responsibility, and if they cannot do much if they leave out if they hide information because of mental or social reasons. The contract has different items on both sides, and they are also implicit. A clear, well-known, and both side accepted contract would need, where the patient is an active agent in the healing process, who is supported by the physician in decisions. These ideas lead to the concept of e-patient.

Google patient is the first step in becoming an e-patient. They know what they are talking about with the doctors and share their condition with the patients' community. Majority of the population is probably a google patient because they use search engines to get more information about themselves. It depends on communication with doctors and cultural norms on how they can use this new information.

„The good patient of the future will:

- Bring lists of questions to the consultation and will expect answers in clear terms

- Know how involved they want to be in decisions about their health care; most will choose to share decisions with their healthcare providers

- Have free access to their health record on paper or through electronic means and will use it or share it as they see fit

- Request and receive a second opinion whenever they face a major diagnosis or decisions about treatment

- Use telephone, internet, and other forms of communication to complement personal visits with members of the healthcare team" (Jadad, 2003. p. 1293)

Most of the doctors label these patients as not a good patient (Jadad 2003), but "healthcare cannot really advance without physicians letting their patients help themselves and be a full partner in making the decisions that affect them." (Meskó, 2014 p. 21) According to Kazai (2012), there are three types of patients:

- Who thinks about the physician as an almighty God, and has all the responsibility in health issues.

- Who has an external locus of control, and thinks he has no influence over his physical or mental state and behaves in a defensive, uncooperative way.

- Who has an internal locus of control and feels responsible for healing.

Evolving e-patients from Google patients is the physicians' responsibility. The e-patient wants to cooperate with the physician and wants to take part in a bigger community, namely the 
group of people with a similar condition to make the experience of all patients better. (Kazai, 2012)

A doctor has a good attitude toward the patients if he lets them help and teaches them selfhelping. "Strategies for promoting an active role for patients should pay attention to health literacy, shared decision-making and self-management." (Coulter et al., 2008 p. 0.)

\section{Methods}

Due to the complexity as mentioned earlier, we chose the qualitative approach and conducted one to two hours of in-depth interviews. We analysed the transcripts with a grounded theory based method when we looked for codes and categories to map the "inside knowledge" of the respondents. (Charmaz, 2013) There are many approaches in the grounded theory because the different fields use different methods. In our research, we use the guidelines of Strauss and Corbin (2008), which allows the use of existing concepts in literature, and both the inductive and the deductive logic is useable. We raised the validity with the analysis of two independent researchers. They both coded the text separately before they reconciled their analysis results. During a thorough study of the transcripts, researchers search for the concepts (so-called codes) that are answering the research question in the text, as well as taking notes (so-called memos) about all of their emerging ideas. Based on the first results the related codes make categories, and the researchers choose the key categories answering the research question and describe the relations between categories to create a new model (Charmaz, 2013). We used a constructivist interpretative approach, we have studied the meaning, intentions, and actions of the respondents, and we tried to follow the direction from the data. "Ontological realism states that the variables studied exist independently of the individual and are therefore specific, objective and measurable. On the contrary, the interpretivism assumes that the human being is not only passively responds to the external reality, but through the inner perceptions and thoughts it is examining the outside world, thereby actively creating its own reality." (Horvath, Mitev, 2015, p. 97) This concludes that with the grounded theory method someone cannot test hypothesises, but can describe how the subjects of the research interpret the reality. (Horváth, Mitev, 2015)

We used the snowball method and the qualitative method of grounded theory at the same time. This means the emerging data influence the subject and the questions of the next interviews. We made an in-depth interview with six patients in university offices, instead of the buildings related to the healthcare system. This way we tried to decrease the environment evoked inhibitions.

\section{Sample}

We aimed to consult well-educated patients with severe illnesses because we believed that the severity of the disease would provide enough motivation to gather information from the Internet about potential therapies and they were probably able to interpret the scientific sources because of their primary professions. Available patients got into the sample without using any age, sex or other quotas. Patients got an ID Number in the study to preserve anonymity and we refer them as this number in parenthesis after quotes in results. 
Table 1: Participants of the study

\begin{tabular}{|l|l|l|l|l|}
\hline ID Number & Sex & Age & Field of work & $\begin{array}{l}\text { Most important medical } \\
\text { problems }\end{array}$ \\
\hline 1 & Woman & $60-70$ & higher education & diabetes, hypertonia, stroke \\
\hline 2 & Woman & $60-70$ & health care & cancer \\
\hline 3 & Woman & $40-50$ & health care & hip surgery, CMT \\
\hline 4 & Woman & $60-70$ & public education & cancer \\
\hline 5 & Woman & $60-70$ & chemical engineering & cancer \\
\hline 6 & Man & $60-70$ & genetic research & cancer \\
\hline
\end{tabular}

Source: own construction

\section{Results}

All patients searched for information, from experienced relatives, friends, books, search engines like Google, and as a result, we believe that the information asymmetry between the doctor and the patient has been decreased. They gathered much information about their illness, possible therapies, but nobody dared to discuss this with the doctor. The reasons were many: lack of time for the doctors, the gratitude for served out of turn, the paternalistic style of the doctor, the lack of the possibility of questioning and the patients existing cultural patterns. In most cases, communication remained one-way. All this caused tension, uncertainty and dissatisfaction in the patients. After analysing the interviews, the following categories of data were created.

\subsection{Gathering medical information from different sources}

All respondents gathered information about their illness. Most of them searched on the Internet, but they used books and their social network too. Despite their knowledge they did not dare to tell the doctor what they have found.

"I got the papers, I went home, I turned on the Internet and looked for stage two, this or that type, how many centimetres, so I gathered the information from the Internet. Despite all the pleasant atmosphere and empathy, there was no time there to explain myself at a high level that I am in trouble. However, I could understand it." (3)

The fourth interviewee suffers from a rare, special illness that has not been diagnosed by her doctor. She realised that her sister has the same illness, so she suggested it for her doctor:

"Now the specialisation is very typical, and the thing is so scattered. I think the patient has to be strongly involved in the process to find the right direction." (4)

This comment is very similar to the most famous e-patient slogan, which is also the title of deBronkart's (2018) book: "Let patients help". Tom Ferguson also describes this approach in several of his works, and even claims that e-patients may "heal” the healthcare system. (Hoch, Ferguson, 2005)

\subsection{Getting medical information from doctors}

The interviewees first were partly satisfied with the information, but as they began to learn about their state and contacted new and new healthcare professionals, more and more shortcomings were discovered. Initial confidence was overwhelmed by a series of 
disappointments due to the hasty, incomplete informing and the fast, enforced decisions. They felt, they do not get time to think, and they are not daring to ask for it even if dosing of "almost lethal drugs" (Mukherje, 2017) was on the stage. The different specialists gave different information about the same topic which also shook the patient. Most of the patients accepted incomplete information to get the treatment quicker and feared to ask questions. It is essential for our research to describe the quality of how the patient is informed, and from where they get information about the therapy.

"All that I have learnt was from the Internet. It was not immediately clear how important is the rehabilitation, because I was misdiagnosed and misinformed, and I should have struggled to get into rehabilitation." (1)

"Obviously, there was no sitting down to consult. Madam this comes from the milk ducts, and it is deadly in that ratio. If we do this surgery, then that will happen. However, this is a forgivable sin, because there were so many patients." (3)

"At 8.00 a.m. they pushed me in the surgery room. So, all you know was, this is the solution, they do the surgery" (3)

Sometimes the physician used one-way, hard to understand messages:

"Surgeons said it is 99\% that it is operated and all right, the oncologist said I could be sure only after preventive chemotherapy. The surgery is $60 \%$, and we can raise it to $95 \%$ with chemotherapy. I have never understood how the percentages are calculated, one time this way, other time that way" (4)

"They sent me away as everything is all right, and it made me very happy. However, they also said I should go to the oncology. Ok, what it is for me. I went there, to the oncology, but "the black soup" came when the doctor said I am in bad condition. The picture is not so clear, and I should take chemotherapy." (3)

Sometimes the physician asked for a serious decision based on cursory information:

"Chemotherapy is needed, and there are two kinds of it. I can take the stronger drug, but the weaker preserves the hair, but the former is better. I said, ok, if I bear it, I take the stronger, but that is all the information I had have. It would be good to get a brochure because it was serious. Communication always goes south, you must decide right there, and you cannot form the right questions. Someone does not think about permanent side effects that come up during the process. The picture is not so bright that I suffer and get healthy again at the end of it." (3)

"The oncologist was an outstanding professional, but he was not so communicative. [...] But otherwise, he was cute and then I asked if I could ask? No! he answered." (3)

\subsection{Paternalism as patients see it}

Patients believed that the information they gathered could not affect the therapy. They considered the best to undergo the doctor's decision. Patient (4) found scientific proof that she should have got fewer chemotherapy sessions. To the question, about mentioning this to the doctor, she gave the following answer:

"No, why? I am not a doctor. If he thinks, it is OK for me, then of course." (4)

Patient (1) discovered that, according to the online sources, his healing chances had deteriorated a lot without neurological rehabilitation. He did not discuss it with the doctor, because: 
"No, it is not possible because they are so eager for themselves. They think the patient is stupid." (1)

Most of the patients are emphatic with the doctor because they see the mass of other patients waiting for treatment. All respondents tried to use their social networks to get better treatment. Therefore they felt they should tolerate incomplete communication. They were fast-tracked, so they were very grateful. They feel they have no right for assertive communication. This is also ensured by the frequent usage of the paternalistic model in doctor-patient relationships.

\subsection{Out of turn service and parasolvency}

We did not aim for it, but it became apparent, that every patient used some social of financial resource to get better or faster service.

"I was in a privileged situation because I worked at the surgery and they started the operations with me, and they talked nicely and, clearly. He told the facts, and I expected this. I was in a lovely community." (2)

"I was called immediately, so there was no wait. I was so surprised, but I was a patient served out of turn. If someone is not, then they can wait for more, or they get in a maze [of burocracy]" (3)

"I went in, and we sit there in a corridor, there was no space. Then he separated slowly who needs surgery soon, who stayed there. Then they sent some of them to home, there was an old lady from Baja, she was a teacher, and she was alone, but they sent her away to came back after a week." (3)

"We did not really have an appointment. Last night I called the professor about my case and the next day he sat down with us for an hour. It is a madhouse, and it became a terrible grinder. It has changed a lot over the past 16-18 years. Oncology patients' number raised skyhigh." (5)

"The parasolvency caused me a constant headache from the beginning. I never knew what to hell should I do about it." (6)

"There worked the wife of a subordinate of mine as a doctor, so they gave me more attention" (6)

\subsection{Trust}

Patients trusted their doctors at the beginning and even the whole system despite their knowledge about the difficulties. They were not jay customers (Lovelock, 1994) who want to ruin the service for themselves or others. Later communication errors made them disappointed.

"I trust, that he will do everything, what is meaningful and rational and will not overdo so that he will do it with the necessary focus" (6)

"I told him, I am pleased, that I get the chemotherapy and I hope that thing is as strong as it is possible. I said that because I felt that way. I can get the strongest chemotherapy to get over this illness finally." (2)

Patient (5) talked about the suggestion of major surgery:

"This was staggering for the first time, but otherwise he presented it with such empathy. It was clear to me that this is the best way to go. He did not recommend anything else because he thought it is the best way to go and it happened soon. I think he made the surgery easy for me 
in all aspects, getting ready for surgery, then spending time hospital, it was an excellent doctor-patient relationship." (5)

"We do not want to revise their knowledge. It is far from that. I think it is vital to have a doctorpatient trust. The patient should trust that the doctors look after everything and everything will be all right." (4)

"Two people meet, and this personal sympathy can recolour or overwrite the doctor-patient relationship because it is important. The other thing, beyond this sympathy, he was very trustworthy. I asked if I did not understand something, and he answered. So, it worked for me, and I did everything in a way he told me." (5)

\subsection{Empathy with the patient}

The most praised and missed category was the positive affiliation., the positive emotional attitude of communication between the parties. In the eyes of the patients, the good the doctor is a well-known concept and they have a positive attitude in most cases. The most important thing next to expertise was empathy with the patient:

"They were very attentive, they told me to lie down, it will hurt a bit" (2)

"He said I do not have much hope. However, with empathy, so not in a gloating way" (3)

"First time it shocked me, but otherwise he presented it with such humanity, it was obvious, that this is the best way for me" (5)

"I investigated who was that young doctor because she was overly likeable. She understood my fright that I am over the edge. She is so young, and she feels empathy towards the patient." (6)

"[The doctors] cannot die with every patient and cannot join the patients in all their sufferings, because then they would not be able to live, work or do anything. They must develop professional behaviour, and you cannot resent it, but it is better for you to meet someone who understands that there were better things in your life." (6)

Sometimes patient expected empathy, but they did not get it at all, or in a way, they would like it:

"If he would have been empathic when I asked for the strongest chemotherapy, then he would have told me, that they give me the best chemotherapy for me at the moment" (2)

"The nurse said this is the E.R., not a luxury hotel, and she did not give me my nose drops [...] My left arm did not work, it was paralytic, but in the bed, I could not sit up. I asked for a bed where I can support myself with my right arm. There were such free beds, but they told me it is not possible because my bed is unmovable in the computer system" (1)

\subsection{Lack of time}

Each respondent felt that the doctors suffer from lack of time. It was not clear how much time available for consultation, so they did not dare to ask essential things, and they responded mainly to the doctor's questions, but did not dare to share their knowledge or experience.

"He was in a hurry, but he said what is needed. That was a huge slap when he said what kind of surgery is this. That time I hoped it is a diagnostic error, only an inflammation, maybe they remove a clot, but he said it is a mastectomy." (3)

Patient (4) himself was a worker of the healthcare industry, and he gathered information about his illness. The question was that he could discuss these with the doctors, but he said: 
"Well, you cannot discuss every important thing. Let's say there are four hours of waiting, and then you know a bunch of people are still waiting outside. So, no that is not the case. We arrange the primary goals, but we cannot discuss the details." (4)

Patient (5) blamed the lack of time for the less than expected empathy:

"Despite all the pleasant atmosphere and empathy, there was no time to explain to me that I am in trouble, but I could understand that." (5)

"One of the greatest of their enemies is the lack of time, I think. The other is, and that one comes from the lack of time too, that even if they are good enough psychologist or they know people, but still they do not know when and how much they should talk" (5)

Patients have noticed the exhaustion of doctors, the many other patients. They felt they should finish the consultation as soon as possible. This has made them uncertain to ask or make suggestions. They felt the lack of time but could not prepare for the discussion because they did not know they have one minute or ten. This makes them disoriented, and they think twice before interrupting the doctors.

"patients should be aware of when and how they seek or whether they want or want to enforce their ideas" (2)

\subsection{Deprivation from hope}

Dehumanisation makes the communication professional but not gives attention to the patients' psychological needs. They try to accept their new state, but they feel they do not get any emotional support, but only a bunch of facts and rules hard to understand.

"They said: we cannot give you powerful chemotherapy, because what if a tumour reappears, then what we will give? I went there with the hope of the perfect chemotherapy what makes me $200 \%$ healthy because the $100 \%$ was reached by the surgeons" (2)

"I had no trust in the system at all. After the nurses did not bring any bedpan, they did not come there, and the head nurse was the same. The doctors were also deaf, no matter what, they just pretended as if they had not heard anything." (1)

"For example, communication was horrible. When you ask after the diagnosis what should you do, how can you help? Moreover, the doctor just told me: well, this is it, Mom, this must be accepted." (3)

\subsection{Fear, vulnerability, humiliating situations}

Most of the interviewees reported some sort of hostility, abuse, humiliation, denial of basic needs, or ruthless honesty. Hospitalisation moves the patients in a new, unknown situation. Rules and rights are well known for the staff, but hard to get used to for the patients. Therefore, they feel vulnerable and sometimes humiliated when they contact the staff who are suffering from burnout syndrome.

"My nose plunged, and I told the nurse that the nose drops are in my bag. She said: What do I think? This is an ER, not a luxury hotel and she did not give my nose drops." (1)

Patient (2) had several surgeries, but after a time the doctor just deprived all hope with one sentence:

"Do you think anyone will dare to do another surgery on you?" (2)

Patient (6) was the victim of hospitalisation: 
"It was an overly humiliating treatment in a very odd place. All the nurses go up and down because they do all kind of stuff, but every patient is naked in practice. They are covered partially, but it does not matter much. [...] This is shocking for me, but who works there, who see such things twenty times a day, or thirty [...] It is impossible without getting used to it on a level. It changes what is appropriate or dignified behaviour. This is not the same as in the outside world, and you have to take it." (6)

"Came a terrible voice and started to scold everybody awfully. I told him: please tell me why you are angry with me, I did not hurt anyone. It turned out that she was simply exhausted and edgy because she has to work too much." (6)

\subsection{Medical malpractice}

In 30 per cent of medical malpractice poor communication was a factor in the United States. (CRICO Strategies 2015) We see no reason to say it is less in Hungary. Patient (1) talked about misdiagnosis and old misconceptions:

"After the CT the neurologist was very kind, he said I have no stroke, but I had a stroke." (1)

"I asked why I did not get eggs in my diet, and they said it raises cholesterol level. This is a fifty-year-old bad habit, and it is not true at all." (1)

In the case of the patient (6), not all the tumours were diagnosed, so they had to do the surgery twice. After the first surgery, he did not heal, but he was able to self-observe the possible location of the tumour. He did not tell it openly but tried to make the doctor check that place too.

"I played stupid because I did not want to tell her to look where she has not seen it before." (6)

It turned out that the patient was right, but they remained silent about it:

"Well, he did not mention it, but we both knew that he botched this. He did not notice that tumour, but he did not apologise." (6)

\section{Discussion}

The best practice of communication emphasises the community between the parties. The essence of communication is that the parties strive for a common understanding of information and thoughts as human relationships develop and the parties influence each other (Málovics, Farkas, 2012). According to the interviewees, the doctors and patients need a common ground in the diagnostic section.

In our cases, this diagnostic section felt short from the patients' viewpoint. This was tolerated at the beginning, but when patient felt misinformed about important things, or could not ask questions, or enforced to decide hastily, then the trust in doctors and satisfaction with the service decreased. Doctors follow the medical protocol, but many times it is not optimal for the individual needs. More than one time the patients noticed medical malpractices. Patients remained silent about these things most of the time because of the lack of time for consultations or the experienced power asymmetry. They differentiate the good doctor (empathic, friendly, conscientious, knowledgeable) who is appreciated, and they think unfriendly acts are mainly because of the hostile environment, the context.

Patients believe that only paternalistic communication is possible in health care services. So, they submit to the medical decisions, but they start to gather information on their own. They evaluate the healing process, the health care service, the communication of doctors and other staff. They gather information from the Internet, social networks, books, other patients. They 
share their experience, and they see the problems of medical science and the health care system. They do not dare to argue or ask questions to the doctors. They are under stress and confused, they do not know the time frame of the consultation. Based on the functional model of communication, the patients perceive an asymmetric control distribution for the sake of doctors. They perceive both positive and negative affiliation.

The patients need to know the time frame of consultations, and they want to know what to tell and ask in these situations. The answer to our research question is that every patient we met is a Google patient who actively cares with the healing process, but the communication happens in a paternalistic way so they cannot become e-patients. Education of both sides is needed to change communication and thereby raise health service quality.

This study is only the first step. Our sample was small, only contains older patients with severe problems and we did not control the place of medical service. It is not about a specific clinic or medical area, but about the collective experience of these people about the public healthcare system. Becoming an e-patient is difficult even for motivated patients because of the paternalism in communication.

\section{This research was supported by the EU-funded Hungarian grant EFOP-3.6.1-16-2016- 00008.}

\section{Reference}

BALINT, M. (1957). The doctor, his patient and the illness. Oxford, England: International Universities Press.

CHARMAZ, K. (2013). Lehorgonyzott elmélet. In: Bodor P. (szerk.) Kvalitatív kutatási olvasókönyv Szavak, képek jelentés. Budapest: L’Harmattan Kiadó., 2013.

CORBIN, J. and STRAUSS, A. (2008). Basics of qualitative research: Techniques and procedures for developing grounded theory. 3rd ed. Thousand Oaks, CA: Sage Publications., 2008. https://doi.org/10.4135/9781452230153

COULTER, A., PARSONS, S., ASKHAM, J., and WORLD HEALTH ORGANIZATION. (2008). Where are the patients in decision-making about their own care? (No. EUR/07/5065810). Copenhagen: WHO Regional Office for Europe., 2008.

CRICO STRATEGIES (2015). Malpractice Risks in Communication Failures. 2015 Annual Benchmarking Report. Boston, MA, CRICO Strategies, 2015.

CSABAI M., CSÖRSZ I., and SZILI K. (2009). A gyógyító kapcsolat élménye. Budapest: Oriold \& Társai Kiadó., 2009.

DEBRONKART, D. (2018). Engedjük a beteget segíteni. Smashword Edition., 2018.

ENGELEN, L. (2014). Foreword by Lucien Engelen in: Meskó, B. (2014) The guide to the future of medicine: technology and the human touch. Webicina Kft., 2014.

FERGUSON, T (2007). E-patients: how they can help us heal healthcare. Robert Wood Johnson Foundation, San Francisco: CA. Available from: https://participatorymedicine.org/ePatient_White_Paper_with_Afterword.pdf, 2007.

HERRMANN, M. J., WELKE, S., SEGEBRECHT, and SCHWANTES, U. (2005). Let's talk about Risk Risikokommunikation in der Hausärztlichen Kardiovaskulären Prävention. PPmPPsychotherapie.Psychosomatik·Medizinische Psychologie. 2005, Vol. 55, No 2, s. 1-56. https://doi.org/10.1055/s-2005-863492

HEWITT-TAYLOR, J. and BOND, C. S. (2012). What e-patients want from the doctor-patient relationship: content analysis of posts on discussion boards. Journal of Medical Internet Research, 2012, Vol. 14, No. 6, s. 155. https://doi.org/10.2196/jmir.2068 
HOCH, D. and FERGUSON, T. (2005). What I've Learned from E-Patients. PLOS Medicine, 2005, Vol. 2, No. 8. s. 206. https://doi.org/10.1371/journal.pmed.0020206

HORVÁTH D. and MITEV, A. (2015). Alternatív kvalitatív kutatási kézikönyv. Budaest: Alinea Kiadó., 2015.

JADAD, A. R. (2003). I am a good patient, believe it or not. BMJ, 2003, Vol. 326 No. 7402, s. 1293 1295. https://doi.org/10.1136/bmj.326.7402.1293

KAZAI A. (2012). Google páciensből e-páciens. Medical Online. nov. 04. Available at: http://medicalonline.hu/informatika/cikk/google_paciensbol_e_paciens, 2012.

KINCSESNÉ VAJDA, B. (2013). Kommunikációs, kapcsolati és egyéni tényezők az egészségügyi szolgáltatások minőségében és kimeneteiben. doctoral dissertation, University of Szeged, 2013.

KLEMPERER, D. (2005). Shared Decision Making und Patientenzentrierung-vom Paternalismus zur Partnerschaft in der Medizin. Balint Journal, 2005. Vol 6., No. 3, s. 71-79. https://doi.org/10.1055/s-2005-871310

LE FANU, J. (1999). The rise and fall of modern medicine. London: Little, Brown \& Co., 1999.

LOVELOCK, C. H. (1994). Product plus: How product and service equals competitive advantage. New York, NY: McGraw-Hill, 1994.

MÁLOVICS, É. and FARKAS, G. (2012). Szervezeti viselkedés. Szeged: JatePress Kiadó, 2012.

MESKÓ, B. (2014). The guide to the future of medicine: technology and the human touch. Webicina Kft., 2014.

HEJDUKOVÁ, P., KUREKOVÁ, L. (2017). Performance and sustainable of healthcare systems and approaches to its measuring and evaluating. International Journal of Social Sciences, 2017, Vol. 6, No. 2, s. 32-43. https://doi.org/10.20472/SS2017.6.2.003

SCHWARTZ, B. (2016). On the paradox of choice Available at: https://www.ted.com/talks/barry_schwartz_on_the_paradox_of_choice, 2016. 